\title{
Characteristics of 2-D convective structures in Catalonia (NE Spain): an analysis using radar data and GIS
}

\author{
M. Barnolas ${ }^{1,2}$, T. Rigo ${ }^{2}$, and M. C. Llasat ${ }^{1}$ \\ ${ }^{1}$ GAMA Team, Dept. of Astronomy and Meteorology, Univ. of Barcelona, Avda. Diagonal, 647, 08028 Barcelona, Spain \\ ${ }^{2}$ Servei Meteorològic de Catalunya, Barcelona, Spain
}

Received: 24 April 2009 - Published in Hydrol. Earth Syst. Sci. Discuss.: 3 July 2009

Revised: 9 December 2009 - Accepted: 16 December 2009 - Published: 21 January 2010

\begin{abstract}
Flood simulation studies use spatial-temporal rainfall data input into distributed hydrological models. A correct description of rainfall in space and in time contributes to improvements on hydrological modelling and design. This work is focused on the analysis of 2-D convective structures (rain cells), whose contribution is especially significant in most flood events. The objective of this paper is to provide statistical descriptors and distribution functions for convective structure characteristics of precipitation systems producing floods in Catalonia (NE Spain). To achieve this purpose heavy rainfall events recorded between 1996 and 2000 have been analysed. By means of weather radar, and applying 2-D radar algorithms a distinction between convective and stratiform precipitation is made. These data are introduced and analyzed with a GIS. In a first step different groups of connected pixels with convective precipitation are identified. Only convective structures with an area greater than $32 \mathrm{~km}^{2}$ are selected. Then, geometric characteristics (area, perimeter, orientation and dimensions of the ellipse), and rainfall statistics (maximum, mean, minimum, range, standard deviation, and sum) of these structures are obtained and stored in a database. Finally, descriptive statistics for selected characteristics are calculated and statistical distributions are fitted to the observed frequency distributions. Statistical analyses reveal that the Generalized Pareto distribution for the area and the Generalized Extreme Value distribution for the perimeter, dimensions, orientation and mean areal precipitation are the statistical distributions that best fit the observed ones of these parameters. The statistical descriptors and the probability distribution functions obtained are of direct use as an input in spatial rainfall generators.
\end{abstract}

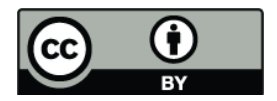

Correspondence to: $\mathrm{M}$. Barnolas (mbarnolas@meteo.cat)

\section{Introduction}

Hydrologists need to generate rainfall synthetic events for many purposes as water resource management and flood modelling, required to obtain maxima flood extensions and for a correct design of infrastructures.

Today hydrometeorologists have two main tools to estimate rainfall; rain gauge and weather radar data, both with their strengths and weakness. Despite rain gauges measure rainfall data accurately, this information is punctual. To get rainfall charts it is necessary the use of interpolation methods which associate rainfall values to non monitored areas with a consequent loss of spatial accuracy. The denser the network, the higher is the spatial resolution. Weather radar is the better option when the spatial variability gets importance, for example in little basins or in regions where convection is important. The problem of using radar data is that it is an indirect measure of rainfall, giving worse results of rainfall depths in a given location than rain gauge data (Krajewski and Smith, 2002). In this way, many studies have been realized in order to minimize radar errors (Chumchean et al., 2006; Morin and Gabella, 2007; among others).

Depending on the availability of data and the hydrological purposes, different kinds of rainfall models are developed. Single-site models are used to represent the temporal evolution of rainfall at a single station (Rodriguez-Iturbe et al., 1987, 1988; García-Bartual and Marco, 1990), and in IDF (intensity duration frequency) analysis (García-Bartual and Schneider, 2001). Multi-site models (a generalization of single-site ones) are used in regions where radar data are not available, or in small basins with dense raingauge networks (Willems, 2001). Syed et al. (2003) use a multi-site model to characterize convective rainfall cells and to relate their geometric parameters to runoff. A multi-site model, using a 5-min aggregated automatic network, is used to model highly convective events in the Jucar river basin, located in

Published by Copernicus Publications on behalf of the European Geosciences Union. 
Eastern Spain (Salsón and García-Bartual, 2003), concluding that radar data will improve the results related to the spatial description of rainfall. Spatio-temporal models are suggested when radar data is available, especially when synthetic events are used as input of distributed hydrological models, for extraordinary flood simulations or for studies where spatial variability is analyzed. These models are based on a hierarchical structure where rainfall fields are described in three levels of rainfall entities with different spatial scales: rain cells, storms and the rain event (or rainfall field). From a hydrological point of view, rain cells are areas of intense precipitation which cluster within storms. Storms are the largest connected rainy areas in a radar image. They cluster within the rainfall field in a similar way as cells do in the storm. From a meteorological point of view, and considering the hydrological purposes (in the rainfall model only two-dimensional spatial regions are needed), rain cells can be associated to convective structures (hereinafter used indistinctly). Convective structures are entities of convective precipitation identified in the lowest level using 2-D radar algorithms (Steiner et al., 1995; Biggerstaff and Listemaa, 2000; Rigo and Llasat, 2007). The largest connected rainy areas in a radar image are also known in meteorology as precipitation structures.

The model of Cox and Isham (1988) has a single level of clustering where each storm consists of a random number of cells. Rain cells are circular with a constant value of intensity over them. They arrive in a Poisson process in space and time, and they move with the same velocity. The rain cell structure is also represented by a circle in Morin et al. (2005, 2006), where rain intensity field has a two-dimensional nonnormalized Gaussian spatial distribution with the maximum at the center. Other models more complex represent the shape of the rain cells as ellipses, as in Northop (1998), where rain cell intensity is considered constant over the cell area. In Von Hardenberg et al. (2003) and in Rebora and Ferraris (2006) the average profile of precipitation intensity is exponential in the elliptic cell. The first authors adopt the exponential profile as best choice for convective cells in tropical precipitation and the others for convective cells at midlatitudes. The elliptical approach is also employed by Feral et al. (2000) to study the geometric characteristics of rain cells in the South-West of France.

Further considerations are taken in this work with the analysis of land and sea cells separately, finding no significant differences in their characteristics. In a bigger spatial scale, frontal rain systems over Belgium are analyzed by De Lannoy et al. (2005), to provide a storm model for the region. By merging rain gauge and radar data results can be improved. In this way, the HYREX experiment combines raingauge and radar data to model spatial-temporal rainfall fields (Wheater et al., 2000).

The present study deals with the statistical characterization of convective structures in Catalonia (NE Spain) with the aim of having a mathematical, but physically based, representation of rain cells. This information will be useful to improve the extreme floods modelling. Taking into account that convection is very important on flash-flood production this work is focused on this kind of precipitation, bearing in mind the consideration of stratiform precipitation in the future.

Heavy rainfall events recorded in Catalonia between 1996 and 2000 have been analysed (Sect. 2). By means of weather radar, and applying 2-D radar algorithms a distinction between convective and stratiform precipitation is made (Sect. 3). These algorithms consider three requirements, independent one from another. In the first requirement a reflectivity threshold $(43 \mathrm{dBz})$ is applied. Two other requirements are considered based on the nature of convective rainfall, with a high variability and a great gradient of reflectivity values between close pixels. This consideration supposes a difference between this paper and others (Feral et al., 2000; Capsoni et al., 1987; Capsoni et al., 2008) which describe rain cells only with respect to a rain rate threshold. These data are introduced and analyzed with a Geographic Information System (GIS, in this case in Arc-Info). Only convective structures with an area greater than $32 \mathrm{~km}^{2}$ are selected in order to avoid very small cells. Geometric characteristics of these structures are obtained by approximating the shape of the structure to an ellipse (Sect. 4). Rainfall statistics are also obtained for each convective structure (Sect. 5). Descriptive statistics for selected characteristics are calculated and statistical distributions are fitted to the observed frequency distributions (Sect. 6). Finally, Sect. 7 summarizes the results obtained.

\section{Data description}

Catalonia is typically affected by heavy rainfall events and has the advantage of having the longest meteorological radar data series of Spain. The location of this region, near the Mediterranean Sea (Fig. 1), and its complex orography bring on the generation of high intense rainfall events which usually produce flash-floods when affect steep coastal basins. Since 1901 to 2000 a total of 217 flood events have been produced in Catalonia (Barnolas and Llasat, 2007), from which more than 130 lasted less than a day.

Radar data has been selected to carry out the present study, thus it represents the spatial variability of the precipitation in surface more accurately than rain gauge data. This advantage is particularly important when we refer to heavy rainfall events associated to convective precipitation.

Pluviometric data in surface have been obtained from the Automatic System of Hydrologic Information (SAIH) for the period 1996-2000. This network comprises 126 automatic rain gauges, giving continuous information on accumulated rainfall at intervals of $5 \mathrm{~min}$. Charts for total daily and $\beta$ parameter have been obtained using a kriging method. This parameter, defined by Llasat (2001) represents the rate 


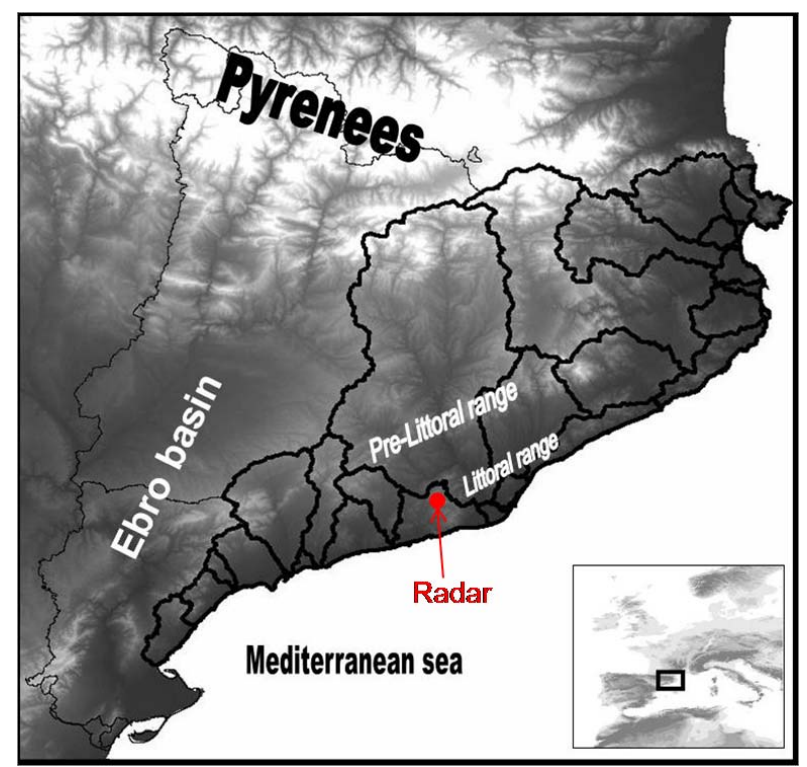

Fig. 1. Main orographic systems and basins of Catalonia.

of convective precipitation to total precipitation, and allows to distinguish between slight convective events $(0<\beta \leq 0.3)$ ,moderate convective events $(0.3<\beta \leq 0.8)$, and strongly convective events $(0.8<\beta \leq 1)$. The events selection has been made in basis to the following criteria: a) a high amount of total daily precipitation above $60 \mathrm{~mm} / 24 \mathrm{~h}$ at least in one rain gauge, b) moderate or strongly convective events in order to include in the selection other kind of events (local and intense ones), that produce floods in the region

The threshold of $60 \mathrm{~mm} / 24 \mathrm{~h}$ follows the recommendations made in the framework of the MEDEX project (MEDEX is part of the WMO- World Weather Research Programme: http://medex.aemet.uib.es/). All these selected events and their convective structures have been analyzed using the meteorological radar.

Radar data is obtained from the meteorological radar of Barcelona, which belongs to the radar network of the Spanish Weather Service (AEMET, former INM). It is situated $20 \mathrm{~km}$ away from Barcelona city, at an altitude of $654 \mathrm{~m}$ a.s.1. It operates in C-band, implementing 20 elevations (PPIs) in each cycle of data collection. From the PPIs an interpolation procedure is undertaken to obtain 12 CAPPIs. Data is collected in periods of $10 \mathrm{~min}$ including a scanning in normal mode (reflectivity) which is the data used in this study. In the normal mode the spatial coverage of the images is $240 \mathrm{~km}$ and the pixel size is $2 \times 2 \mathrm{~km}^{2}$. Because of signal and beam properties, the measure of precipitation is worst as far away is the echo from the radar. For the radars of C-band, as the one the Spanish Meteorological Agency placed closed to Barcelona which is used in this work, the range threshold for the Quantitative Precipitation Estimation (QPE) is $150 \mathrm{~km}$. Using the long range product (until $240 \mathrm{~km}$ ) it is possible to detect thunderstorms which are well-developed in the vertical. In fact, the center of the beam radar is placed at a height between 6 and $8 \mathrm{~km}$ (depending of different factors, such the altitude of the radar) when the distance to the radar placement is $240 \mathrm{~km}$. For this reason, it results impossible to detect stratiform precipitation, and also, convective precipitation associated to orographic triggering (with developments not exceeding the $5-6 \mathrm{~km}$ ). The analysis realized by Trapero et al. (2009) with C-band weather radars in the same region showed that there practically no differences between results of short and long range product, when the QPE is compared with rain gauges values. Images have been treated previously by the AEMET (Sánchez-Diezma, 2001). Ground echoes have been eliminated by the use of a clutter mask. Radar data which is recorded in polar coordinates has been transformed into Cartesian coordinates. Finally, pixels with reflectivity values under $12 \mathrm{dBZ}$ have been removed as the corresponding rain rate value using the Marshall-Palmer (1948) $Z / R$ relationship is close to $0.1 \mathrm{~mm} / \mathrm{h}$. These pixels are not considered as rainfall ones.

Twenty-four events have been selected. Dates, amount of precipitation, $\beta$ parameter in $24 \mathrm{~h}$, and number of available radar images are shown in Table 1 . As there is an instantaneous observation every $10 \mathrm{~min}$, for a complete day 143 images are generated. This amount of images is not always available for different reasons. In some cases the rainfall event did not last the whole day. In other cases the lack of data is due to errors in the images forcing the rejection of them, or due to the existence of gaps in the acquisition of data.

\section{Identification of convective structures in radar images}

Precipitation structures, defined as the largest connected rainy area in a radar image, are isolated, and regions of convective precipitation are identified. Identification of convective precipitation in the lowest CAPPI (Constant Altitude Plan Position Indicator) level has been made applying the RHAP program (Ceperuelo et al., 2006). This program uses the 2-D algorithm based on Steiner et al. (1995) and Biggerstaff and Listema (2000), adapted to the Spanish region by Rigo and Llasat (2004). This algorithm considers three requirements, independent one from another. One of these requirements has to be verified to identify a pixel as convective. Firstly, a reflectivity threshold ( $43 \mathrm{dBZ})$ is applied based on the fact that convective rain rates are more intense than stratiform ones. This threshold can vary attending the radar type and the study zone, but in Mediterranean region it is, usually, near $40 \mathrm{dBz}$. In the case of the radar used in this work, Llasat et al. (2007) showed, after comparing convective precipitation distribution from raingauges (using the $\beta$ parameter) and radar imagery and for all the heavy rainfall cases recorded between 1996 and 2000, that the threshold of $43 \mathrm{dBZ}$ was the most suitable one. The second requirement 
Table 1. Selected days, maximum precipitation recorded in $24 \mathrm{~h}\left(P_{\max } 24 \mathrm{~h}\right)$, maximum $\beta$ in $24 \mathrm{~h}(\beta 24 \mathrm{~h})$, and number of radar images $(\mathrm{N})$.

\begin{tabular}{lrlr|lrrr}
\hline $\begin{array}{l}\text { Date } \\
(\mathrm{dd} / \mathrm{mm} / \mathrm{yyyy})\end{array}$ & $\begin{array}{r}P_{\max } 24 \mathrm{~h} \\
(\mathrm{~mm} / 24 \mathrm{~h})\end{array}$ & $\beta 24 \mathrm{~h}$ & $\mathrm{~N}$ & $\begin{array}{l}\text { Date } \\
(\mathrm{dd} / \mathrm{mm} / \mathrm{yyyy})\end{array}$ & $\begin{array}{r}P_{\max } 24 \mathrm{~h} \\
(\mathrm{~mm} / 24 \mathrm{~h})\end{array}$ & $\beta 24 \mathrm{~h}$ & $\mathrm{~N}$ \\
\hline $22 / 01 / 1996$ & 85.9 & 0.071 & 60 & $28 / 06 / 1997$ & 59.1 & 0.390 & 81 \\
$23 / 01 / 1996$ & 73.2 & 0.126 & 143 & $29 / 06 / 1997$ & 27.1 & 0.377 & 60 \\
$24 / 01 / 1996$ & 55.0 & 0.471 & 58 & $28 / 08 / 1997$ & 54.6 & 0.917 & 47 \\
$28 / 01 / 1996$ & 84.2 & 0.804 & 96 & $01 / 09 / 1997$ & 64.7 & 0.951 & 41 \\
$07 / 05 / 1996$ & 23.8 & 0.638 & 60 & $16 / 12 / 1997$ & 65.1 & 0.396 & 78 \\
$08 / 05 / 1996$ & 27.9 & 0.522 & 37 & $05 / 08 / 1999$ & 23.4 & 0.982 & 22 \\
$14 / 10 / 1996$ & 125.8 & 0.683 & 89 & $06 / 08 / 1999$ & 15.9 & 0.616 & 14 \\
$15 / 10 / 1996$ & 63.5 & 0.443 & 28 & $14 / 09 / 1999$ & 116.5 & 0.890 & 92 \\
$11 / 11 / 1996$ & 90.6 & 0.376 & 90 & $10 / 05 / 2000$ & 94.2 & 0.849 & 69 \\
$12 / 11 / 1996$ & 130.9 & 0.402 & 123 & $10 / 06 / 2000$ & 223.8 & 0.934 & 60 \\
$04 / 06 / 1997$ & 61.1 & 0.605 & 68 & $21 / 10 / 2000$ & 65.0 & 0.552 & 31 \\
$05 / 06 / 1997$ & 75.1 & 0.822 & 59 & $22 / 10 / 2000$ & 161.9 & 0.815 & 90 \\
\hline
\end{tabular}

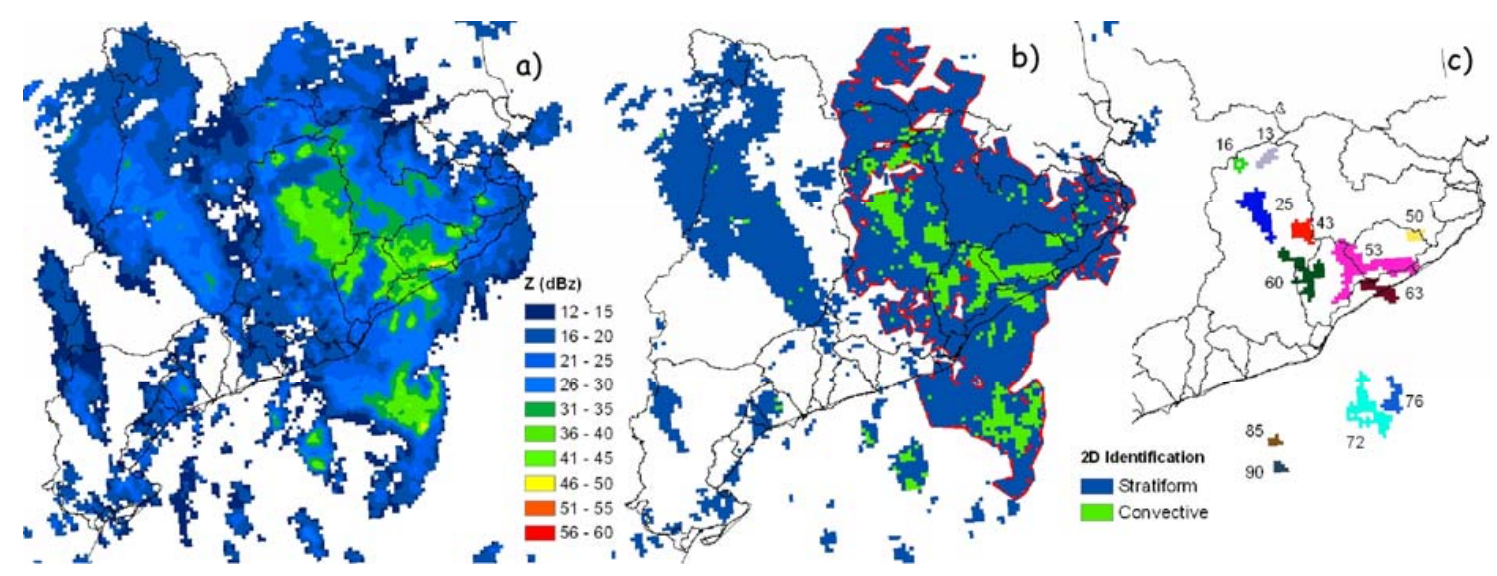

Fig. 2. Different steps of the convective structures identification, for the 15/10/1996 event at 00:00 UTC: (a) Reflectivity image, (b) 2-D Identification image: where green values mean convective and blue ones stratiform precipitation. A precipitation structure is been highlighted in red, and (c) Convective structures detected with an area above the threshold.

is based on gradient criteria. A pixel is considered as convective, even if it does not exceed the reflectivity threshold, if the difference between its value and a mean value of its background exceeds a considered function. This function depends on the background reflectivity and the radar characteristics. In this work, the following function, proposed by Rigo and Llasat (2004) for Catalonia, has been applied:

$Z-Z_{\mathrm{bg}}>8 \cdot \cos \left(\pi \cdot Z_{\mathrm{bg}} / 128\right)$

where $Z_{\mathrm{bg}}$ is the background reflectivity. This requirement tries to take into account the showers of low rainfall intensity that, although being of convective character, do not arrive to the $43 \mathrm{dBz}$ threshold. The third requirement considers that if the pixels adjacent, including left-right, up-down and also diagonal neighbours, to the analysed pixel are convective, the later could be considered as convective. It searches for pixels included in a threshold radius, depending on the reflectivity value of the considered pixel. Those pixels that do not verify any of the three requirements, with a reflectivity value above $18 \mathrm{dBZ}$, are considered as stratiform.

The method used to isolate convective structures in radar images is based on connectivity (Fig. 2). Convective pixels are associated to the same convective structure if the pixels are directly to the right or left or above or below each other, considering the four nearest neighbours. If two pixels of the same nature are diagonal from one another, they are not considered connected. In the resulting image a group of minimum 8 pixels $\left(32 \mathrm{~km}^{2}\right)$ is identified as a convective structure. The value of $32 \mathrm{~km}^{2}$ is chosen to avoid very small ones, most of them associated with anomalous echoes, and to select the most important cells. A total of 1596 radar images are analyzed resulting in a total of 34149 precipitation structures and 13472 convective structures detected (Table 2). 
Table 2. Selected days, number of precipitation structures (NPS) and number of convective structures (N Conv2D) detected each day.

\begin{tabular}{lrr|lrr}
\hline $\begin{array}{l}\text { Date } \\
\text { (dd/mm/yyyy) }\end{array}$ & NPS & N Conv2D & $\begin{array}{l}\text { Date } \\
\text { (dd/mm/yyyy) }\end{array}$ & NPS & N Conv2D \\
\hline $22 / 01 / 1996$ & 1875 & 529 & $28 / 06 / 1997$ & 2136 & 473 \\
$23 / 01 / 1996$ & 5040 & 1610 & $29 / 06 / 1997$ & 444 & 26 \\
$24 / 01 / 1996$ & 1700 & 703 & $28 / 08 / 1997$ & 783 & 152 \\
$28 / 01 / 1996$ & 1246 & 121 & $01 / 09 / 1997$ & 1717 & 466 \\
$07 / 05 / 1996$ & 2825 & 1130 & $16 / 12 / 1997$ & 1634 & 87 \\
$08 / 05 / 1996$ & 1683 & 185 & $05 / 08 / 1999$ & 188 & 114 \\
$14 / 10 / 1996$ & 1476 & 1476 & $06 / 08 / 1999$ & 223 & 211 \\
$15 / 10 / 1996$ & 1017 & 522 & $14 / 09 / 1999$ & 1927 & 1927 \\
$11 / 11 / 1996$ & 2394 & 554 & $10 / 05 / 2000$ & 951 & 231 \\
$12 / 11 / 1996$ & 548 & 548 & $10 / 06 / 2000$ & 1341 & 414 \\
$04 / 06 / 1997$ & 533 & 533 & $21 / 10 / 2000$ & 512 & 125 \\
$05 / 06 / 1997$ & 153 & 153 & $22 / 10 / 2000$ & 1803 & 1182 \\
\hline
\end{tabular}

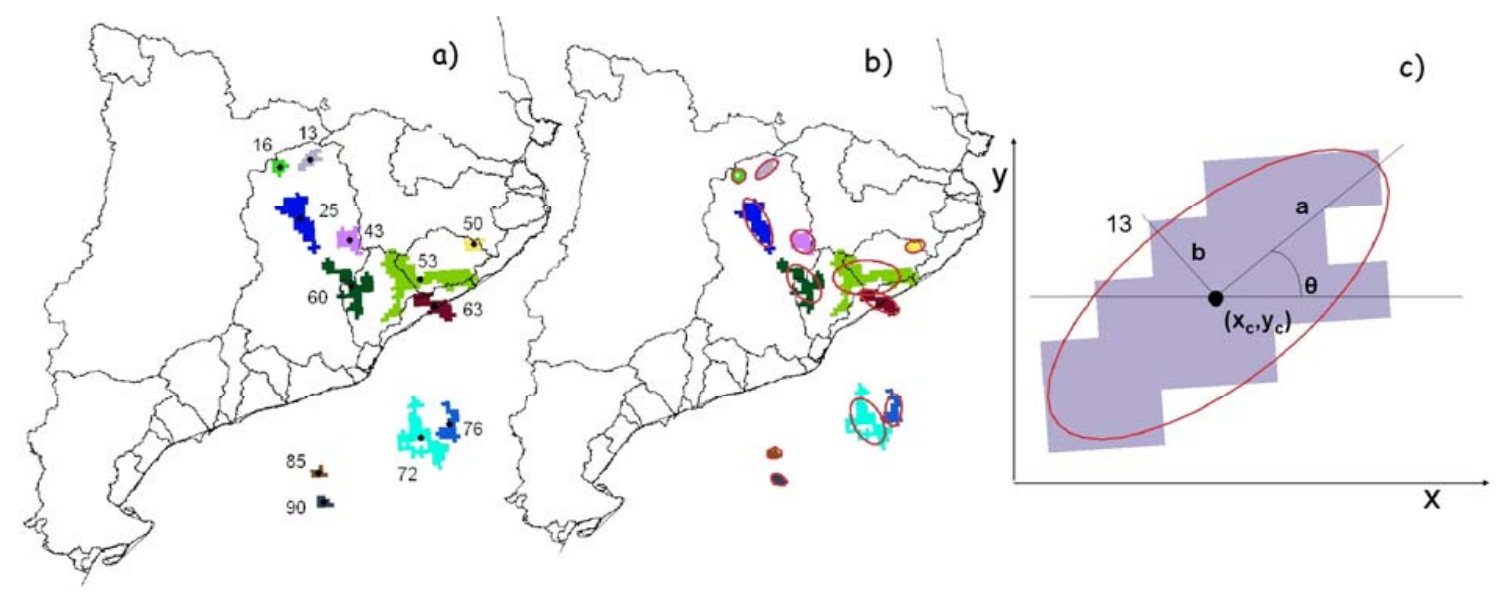

Fig. 3. Geometrical features of convective structures detected for the 15/10/1996 event at 00:00 UTC: (a) centroids of each structure and labels associated to Table 3; (b) representative ellipses of the different structures; (c) zoom of a convective structure and its parameters. Table 3 synthesizes the geometrical features of each structure.

\section{Geometric description of convective structures}

To generate a spatial rainfall model a geometric simplification of reality is needed, since it is very complex. In a spatial rainfall generator, a rain cell is often represented by a circle or an ellipse, as it is shown in the introduction. The circle cell assumption makes easier modelling the spatial distribution of the rain cell intensity field. Even this way, the elliptical cell assumption is desirable since spatial autocorrelation plots of radar data often have elliptical contours (Northop, 1998). In the present study convective structures are described as ellipses.

Geometric description of convective structures has been obtained using GIS. Resulting images from 2-D identification are saved as ASCII files in ArcInfo format, and afterwards transformed in raster files. The canonical analysis (a statistical regression method used to find variables with a high correlation) is used to determine the parameters of ellipses describing the structures. As such, the area of each ellipse is equal to the area of the convective structure to which it is assigned. The shape of the ellipse is the best ellipsoidal approximation of the convective structure (Fig. 3). The center of the ellipse is located at its centroid (xc, yc), which is considered as the mass center. The parameters defining the shape and the size of the ellipse are its major axis ("a" in Fig. 3c) and its minor axis ("b" in Fig. 3c). Orientation $(\theta)$, defined as the angle between the $\mathrm{x}$-axis and the major axis of the ellipse, is also calculated. These values are stored in degrees with the possible range of $0^{\circ}$ to $180^{\circ}$. The values of the orientation angle increase counter clockwise starting at $0^{\circ}$ in the east (horizontal, to the right) and going through $90^{\circ}$ when the major axis is vertical. If a particular structure consists of a single square block of pixels, the 
Table 3. Identification number (ID), Area, Perimeter, Thickness, centroid coordinates (Xcentroid and Ycentroid), major and minor axis (Majoraxis and Minoraxis) and orientation (Ori) of the ellipse, for the convective structures for the 15/10/1996 event at 00:00 UTC.

\begin{tabular}{rrrrrrrrr}
\hline ID & $\begin{array}{r}\text { Area } \\
\left(\mathrm{km}^{2}\right)\end{array}$ & $\begin{array}{r}\text { Perimeter } \\
(\mathrm{km})\end{array}$ & $\begin{array}{r}\text { Thickness } \\
(\mathrm{km})\end{array}$ & $\begin{array}{r}\text { Xcentroid } \\
(\mathrm{UTM})\end{array}$ & $\begin{array}{r}\text { Ycentroid } \\
(\mathrm{UTM})\end{array}$ & $\begin{array}{r}\text { Majoraxis } \\
(\mathrm{km})\end{array}$ & $\begin{array}{r}\text { Minoraxis } \\
(\mathrm{km})\end{array}$ & $\begin{array}{r}\text { Ori } \\
\left({ }^{\circ}\right)\end{array}$ \\
\hline 13 & 68 & 48 & 1.4 & 407959 & 4676990 & 7.16 & 3.02 & 36.76 \\
17 & 40 & 40 & 1.0 & 393300 & 4674470 & 3.64 & 3.49 & 45.00 \\
25 & 236 & 108 & 4.2 & 401375 & 4649140 & 14.06 & 5.34 & 112.90 \\
43 & 116 & 64 & 3.4 & 424141 & 4637420 & 6.77 & 5.46 & 132.50 \\
50 & 52 & 32 & 3.0 & 482285 & 4631020 & 5.11 & 3.24 & 10.64 \\
53 & 496 & 212 & 5.0 & 455852 & 4616390 & 17.37 & 9.09 & 177.52 \\
60 & 240 & 144 & 3.0 & 423200 & 4615470 & 11.53 & 6.62 & 125.97 \\
63 & 136 & 76 & 3.0 & 461841 & 4603520 & 11.17 & 3.87 & 149.61 \\
72 & 304 & 180 & 3.4 & 451242 & 4541630 & 13.00 & 7.44 & 115.23 \\
76 & 112 & 76 & 3.0 & 465114 & 4546660 & 8.56 & 4.17 & 81.53 \\
85 & 32 & 28 & 1.0 & 401650 & 4528120 & 3.81 & 2.67 & 1.79 \\
90 & 36 & 28 & 1.4 & 403122 & 4514430 & 4.31 & 2.66 & 150.48 \\
\hline
\end{tabular}

orientation of the ellipse (being a circle in this case) is set to $45^{\circ}$. Other characteristics such as their perimeter, and their thickness (described as the radius of the largest circle that can be drawn within a structure without including any cells outside the structure), are also defined. Table 3 shows an example of all the parameters obtained for convective structures detected on the 15/10/1996 at 00:00 UTC.

\section{Rainfall field in convective structures}

Surface rainfall data obtained from weather radar has been used to obtain the rainfall field in convective structures. This field is the cumulated value in $10 \mathrm{~min}$ (as it is the radar time resolution). To transform the reflectivity values $Z\left(\mathrm{~mm}^{6} / \mathrm{m}^{3}\right)$ into surface rainfall rates $R(\mathrm{~mm} / \mathrm{h})$ a different MarshallPalmer relation has been used in stratiform and convective rainfall. 2-D identification shown in Sect. 3 has been used to distinguish the two types of precipitation. The different $Z / R$ relations are:

For stratiform rainfall (Marshall-Palmer, 1948):

$P_{\text {str }}(\mathrm{mm} / \mathrm{h})=\left(\frac{10^{\mathrm{Z} / 10}}{200}\right)^{5 / 8}$

For convective rainfall (Llasat et al, 2007):

$P_{\text {conv }}(\mathrm{mm} / \mathrm{h})=\left(\frac{10^{\mathrm{Z} / 10}}{800}\right)^{5 / 8}$

Rainfall field of each convective structure (Fig. 4) is obtained by overlapping the structures identified in each image to the ten previous minutes cumulated rainfall chart. Descriptive statistics of the rainfall field of each structure are obtained using GIS and are saved in a table like Table 4. This table includes the following values for the 10-min cumulated precipitation: maximum $\left(P_{\max }\right)$, minimum $\left(P_{\min }\right)$,

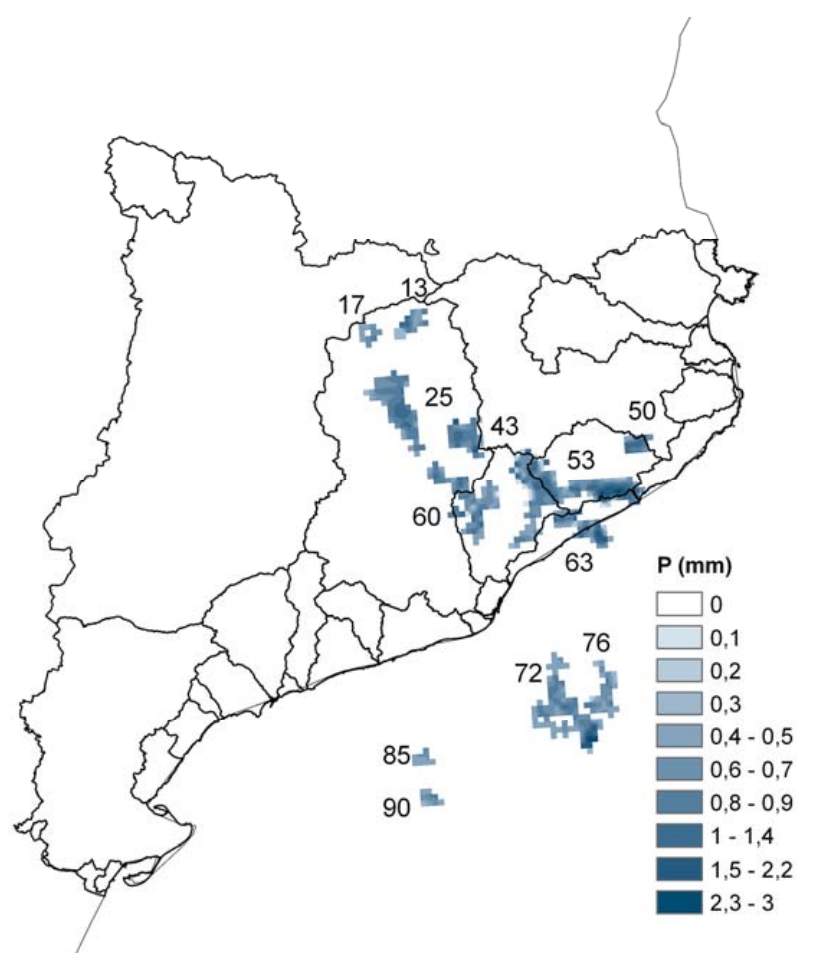

Fig. 4. Rainfall chart for convective structures detected for the 15/10/1996 event at 00:00 UTC. Labels are used to identify each convective structure in Table 4.

mean $\left(P_{\text {mean }}\right)$, mean areal precipitation (MAP), range, standard deviation (STD), and sum of the precipitation recorded in each pixel of the structure. Results obtained for convective structures detected the 15/10/1996 at 00:00 UTC are shown in Table 4. In the spatial rainfall model a constant rate of rainfall over the cell area is assigned. This constant value is the mean value over the cell obtained from the rainfall statistics. 
Table 4. Rainfall statistics for the convective structures of the 15/10/1996 event at 00:00 UTC: Maximum value $\left(P_{\max }\right)$, Minimum value $\left(P_{\min }\right)$, Mean value $\left(P_{\text {mean }}\right)$, Mean Areal Precipitation (MAP), Sum, Range, and Standard Deviation (STD).

\begin{tabular}{rrrrrrrr}
\hline & $\begin{array}{r}P_{\max } \\
(\mathrm{mm})\end{array}$ & $\begin{array}{r}P_{\min } \\
(\mathrm{mm})\end{array}$ & $\begin{array}{r}P_{\text {mean }} \\
(\mathrm{mm})\end{array}$ & $\begin{array}{r}\text { MAP } \\
(\mathrm{mm})\end{array}$ & Sum & Range & STD \\
\hline 13 & 1.24 & 0.22 & 0.58 & 0.0085 & 9.84 & 1.02 & 0.29 \\
17 & 0.70 & 0.39 & 0.52 & 0.0130 & 5.18 & 0.31 & 0.09 \\
25 & 1.24 & 0.30 & 0.72 & 0.0031 & 42.74 & 0.95 & 0.21 \\
43 & 1.66 & 0.39 & 0.76 & 0.0066 & 22.09 & 1.27 & 0.28 \\
50 & 1.24 & 0.45 & 0.80 & 0.0154 & 10.40 & 0.79 & 0.24 \\
53 & 2.95 & 0.03 & 0.75 & 0.0015 & 92.45 & 2.93 & 0.50 \\
60 & 1.08 & 0.06 & 0.62 & 0.0026 & 37.26 & 1.02 & 0.23 \\
63 & 2.21 & 0.14 & 0.74 & 0.0055 & 25.26 & 2.07 & 0.45 \\
72 & 2.95 & 0.30 & 0.70 & 0.0023 & 53.16 & 2.66 & 0.47 \\
76 & 0.81 & 0.19 & 0.50 & 0.0045 & 14.03 & 0.62 & 0.17 \\
85 & 0.61 & 0.34 & 0.48 & 0.0149 & 3.81 & 0.27 & 0.07 \\
90 & 0.70 & 0.26 & 0.51 & 0.0141 & 4.56 & 0.44 & 0.14 \\
\hline
\end{tabular}

\section{Results}

The main objective of this study is the statistical characterization of convective structures in Catalonia. This statistical characterization provides information to be used in a rainfall model. In this model convective structures are described by ellipses, defined by their major and minor axis and their orientation, with a rain cell intensity considered constant over its area. The statistical distributions fitted to the observed frequency distributions of these parameters provide the information needed to generate stochastic rainfall fields analogous to real rainfall fields. Starting from these premises, 13472 convective structures with an area over $32 \mathrm{~km}^{2}$ have been analyzed. These structures have been detected from the study of 24 heavy rainfall events. Although the temporal evolution of convective structures will be analysed, this is not the objective of this paper. This means that each convective structure is detected in one radar image; if one structure lasts more than $10 \mathrm{~min}$, then, it is considered twice or more. Geometric parameters of the structures are obtained for each one of these cells considering the elliptical shape assumption. Rainfall statistics are obtained for each convective structure to study their rainfall field. Descriptive statistics for all these parameters are calculated and statistical distributions are fitted to the observed frequency distributions. Several statistical distribution functions are tested in order to find the best fit. The parameters of the statistical distributions are obtained using the Maximum likelihood estimation method.

\subsection{Geometric characteristics of convective structures}

Regarding the geometric characterization, all the parameters described in Sect. 4 are calculated for each convective structure and merged in a single table. Descriptive statistics obtained for these parameters are maximum and minimum
Table 5. Descriptive statistics obtained for some of the geometrical parameters studied.

\begin{tabular}{lrrrrr}
\hline Field_Name & Mean & Min & Max & Range & SDev \\
\hline Area $\left(\mathrm{km}^{2}\right)$ & 107.19 & 32.00 & 2380.00 & 2348.00 & 148.01 \\
Perimeter $(\mathrm{km})$ & 63.44 & 24.00 & 804.00 & 780.00 & 51.34 \\
Majoraxis $(\mathrm{km})$ & 7.79 & 3.19 & 49.18 & 45.99 & 4.58 \\
Minoraxis $(\mathrm{km})$ & 3.66 & 0.72 & 20.46 & 19.74 & 1.85 \\
Thickness $(\mathrm{km})$ & 2.26 & 1.00 & 13.07 & 12.07 & 1.45 \\
Orientation $\left({ }^{\circ}\right)$ & 81.42 & 0.00 & 180.00 & 180.00 & 47.64 \\
\hline
\end{tabular}

values, sample averages, standard deviations, and range. These results are shown in Table 5. The parameters that will be of direct use in a spatial rainfall generator are: major and minor axis of the ellipse and the orientation. Histograms are obtained for these characteristics and for the area and perimeter.

Area values present a high variation with a standard deviation value higher than the mean value. Even though area values for convective structures lie between 32 and $2380 \mathrm{~km}^{2}$, almost the $80 \%$ of the convective structures have areas of less than $130 \mathrm{~km}^{2}$. In this way, the observed distribution can be approached by a Generalized Pareto distribution, given by:

$f(x \mid \kappa, \sigma, \theta)=\left(\frac{1}{\sigma}\right)\left(1+\kappa \frac{(x-\theta)}{\sigma}\right)^{-1-\frac{1}{\kappa}}$

for $\theta<x$, when $\kappa>0$, or for $\theta<x<-\sigma / \kappa$ when $\kappa<0$. In the limit for $k=0$ the Generalized Pareto is an Exponential distribution.

Generalized Pareto function assumes that there are no values underneath a certain threshold. In this case the threshold value is $30 \mathrm{~km}^{2}$ due to the fact that the minimum value of $32 \mathrm{~km}^{2}$ has been imposed from the beginning. The perimeter, the dimensions and the orientation can be approached by a Generalized Extreme Value (GEV) distribution, given by:

$$
\begin{aligned}
f(x \mid \kappa, \mu, \sigma)= & \left(\frac{1}{\sigma}\right) \exp \left(-\left(1+\kappa \frac{(x-\mu)}{\sigma}\right)^{-\frac{1}{\kappa}}\right) \\
& \left(1+\kappa \frac{(x-\mu)}{\sigma}\right)^{-1-\frac{1}{\kappa}}
\end{aligned}
$$

for $1+\kappa \frac{(x-\mu)}{\sigma}>0 . \kappa>0$ corresponds to the Type II case, while $\kappa<0$ corresponds to the Type III case. In the limit for $\kappa=0$, corresponding to the Type I case, the density is:

$$
f(x \mid 0, \mu, \sigma)=\left(\frac{1}{\sigma}\right) \exp \left(-\exp \left(-\frac{(x-\mu)}{\sigma}\right)-\frac{(x-\mu)}{\sigma}\right)
$$

Most of the convective structures have perimeters of less than $100 \mathrm{~km}$. Concerning the dimensions, the major and minor axis have mean values of $7.79 \mathrm{~km}$ and $3.66 \mathrm{~km}$ respectively. Most of the convective structures have a major and minor 
Table 6. Probability distribution functions and distribution parameters, where MAP is Mean Areal Precipitation.

\begin{tabular}{llrrr}
\hline \multirow{2}{*}{ Parameters } & Distribution & \multicolumn{2}{c}{ Distribution parameter values } \\
\cline { 3 - 5 } & & Scale & Shape & threshold/location \\
\cline { 3 - 5 } Area & Generalized & $35.28 \pm 0.56 \mathrm{~km}^{2}$ & $0.60 \pm 0.01$ & $30.00 \pm 0.00 \mathrm{~km}^{2}$ \\
& Pareto & & & \\
Perimeter & GEV & $14.85 \pm 0.15 \mathrm{~km}$ & $0.56 \pm 0.01$ & $40.00 \pm 0.15 \mathrm{~km}$ \\
Major Axis & GEV & $1.90 \pm 0.02 \mathrm{~km}$ & $0.10 \pm 0.01$ & $5.63 \pm 0.02 \mathrm{~km}$ \\
Minor Axis & GEV & $0.91 \pm 0.07 \mathrm{~km}$ & $0.25 \pm 0.01$ & $2.82 \pm 0.01 \mathrm{~km}$ \\
Orientation & GEV & $44.77 \pm 0.31 \mathrm{~km}$ & $0.22 \pm 0.01$ & $63.28 \pm 0.15^{\circ}$ \\
MAP & GEV & $0.0394 \pm 0.002 \mathrm{~mm}$ & $0.112 \pm 0.007$ & $0.617 \pm 0.001 \mathrm{~mm}$ \\
\hline
\end{tabular}

axis underneath $15 \mathrm{~km}$ and $6 \mathrm{~km}$ respectively. Both parameters can be fitted by a GEV distribution of Type II. Orientation values range between $0^{\circ}$ and $180^{\circ}$, with a mean value of $80.92^{\circ}$. Most of them have orientations of less than $90^{\circ}$, which means that most of the convective structures are facing North East. The frequency distribution of this parameter is best fitted by a GEV distribution of type III. Observed and for these parameters are shown in Fig. 5, while distribution parameter values are shown in Table 6. Parameters of the fitted cumulative distribution functions have been obtained using the Maximum likelihood estimation (MLE) method. All the parameters pass a 5\% confidence Kolmogorov-Smirnoff test, except orientation. In this case it passes the K-S test with a random sample of 400 values (as the K-S test is very sensitive to the number of data). The distribution selected has been the distribution that best fitted the observed histogram, above others as Normal, Lognormal, Weibull, and Gamma distributions.

Using a GIS has permitted to investigate separately land and sea cells. Frequency distributions of geometric parameters (not presented in this paper) do not show significant differences.

\subsection{Rainfall characteristics of convective structures}

Regarding the pluviometric characterization, all the parameters described in Sect. 5 are calculated for each convective structure and merged in a single table. Descriptive statistics are obtained for the minimum, maximum, mean and mean areal rainfall, and for the range of values given in the cells. These statistics, presented in Table 7, show the properties of the 10 min-cumulated rainfall charts in these structures.

Maximum rainfall value presents a lot of variation with a high standard deviation. This parameter ranges between $1.57 \mathrm{~mm}$ and $34.07 \mathrm{~mm}$. Mean rainfall and mean areal precipitation values present lower variation than the other parameters. Observed frequency distributions of these parameters fit better theoretical statistic distributions than the other ones. This fact has favoured the assumption of mean areal precipitation as the constant value over the cell for a given
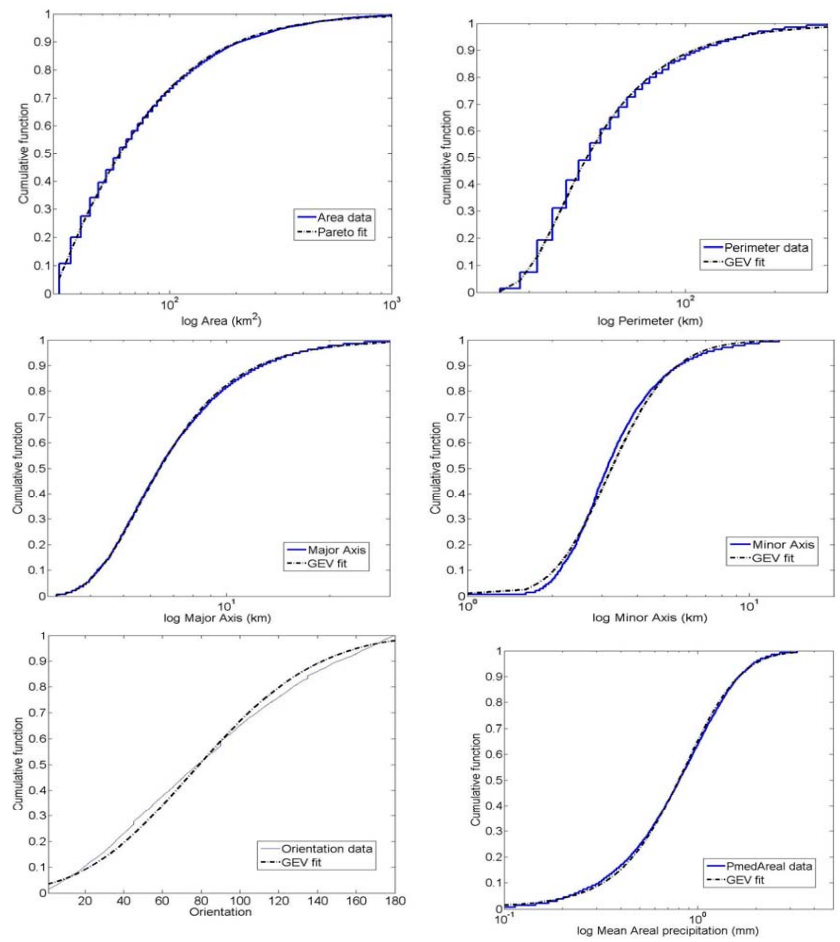

Fig. 5. Observed and fitted cumulative distribution functions for different geometrical characteristics (area, perimeter, major and minor axis, and orientation) and the Mean Areal Precipitation.

area. The distribution observed for the mean areal precipitation can be approached by a GEV distribution (Fig. 5). Mean areal precipitation distribution will be used to obtain the constant value of precipitation over the cell for a given area in the rainfall model. Because this constant value will be used to represent reality, the observed rainfall chart obtained form radar (considering only convective precipitation) is compared to the rainfall chart obtained from the elliptical cells considering mean precipitation constant over the cell. Figure 6 shows these two charts for the 15/10/1996 event. 


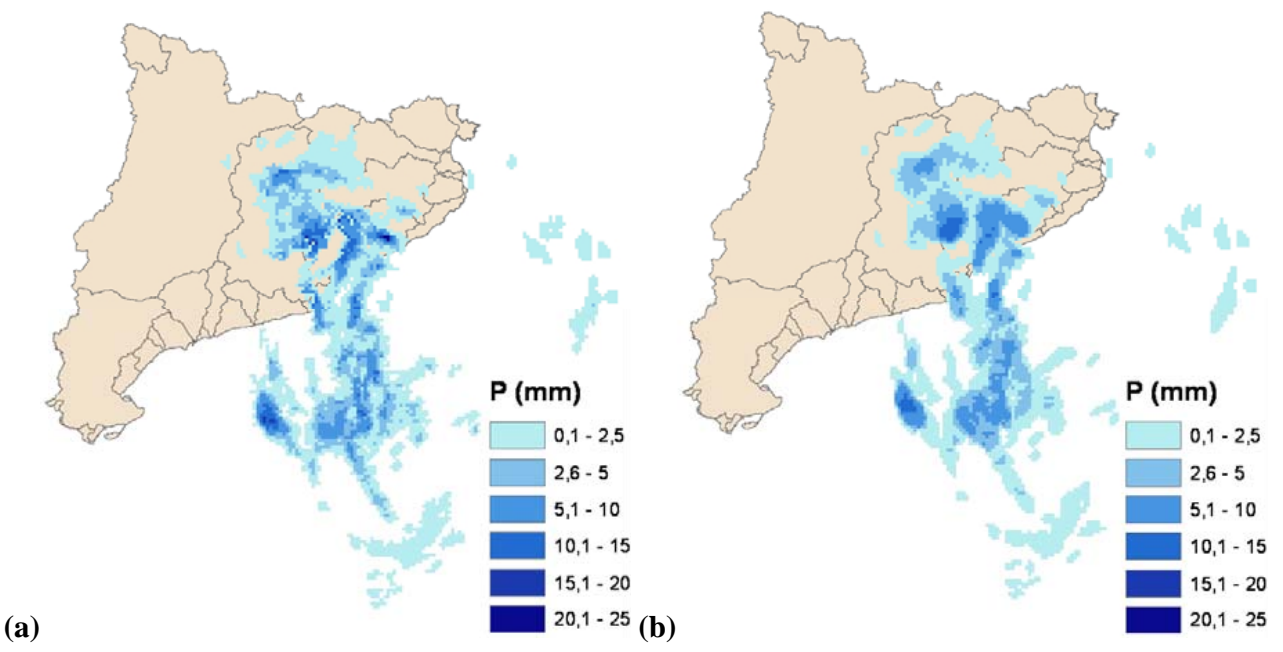

Fig. 6. Cumulated rainfall field for the 15/10/1996 in $4 \mathrm{~h} 20 \mathrm{~min}$, (a) considering convective precipitation of radar images, (b) considering elliptical cells with mean precipitation constant over the cell.

Table 7. Descriptive statistics obtained for some of the rainfall parameters studied. $P_{\min }, P_{\max }$, Range, $P_{\text {mean }}$ and MAP, are described in Sect. 5.

\begin{tabular}{lrrrrr}
\hline Field_Name & Mean & Min & Max & Range & SDev \\
\hline$P_{\min }(\mathrm{mm})$ & 0.221 & 0.003 & 2.555 & 2.552 & 0.100 \\
$P_{\max }(\mathrm{mm})$ & 1.571 & 0.192 & 34.074 & 33.882 & 1.927 \\
Range $(\mathrm{mm})$ & 1.350 & 0.000 & 33.993 & 33.993 & 1.948 \\
$P_{\text {mean }}(\mathrm{mm})$ & 0.617 & 0.192 & 7.128 & 6.936 & 0.345 \\
MAP $(\mathrm{mm})$ & 0.923 & 0.049 & 20.617 & 20.569 & 0.616 \\
\hline
\end{tabular}

To compare both fields a general Q-Q plot of the two variables by pixel, is used (Fig. 7). A Q-Q plot is a plot of the quantiles of the first dataset against the quantiles of the second dataset. It is a graphical technique for determining if two datasets come from populations with a common distribution. For two identical distributions, the Q-Q Plot will be a straight line.

It can be observed in Fig. 6 that the rainfall field obtained considering convective structures as elliptical, has a lower spatial variability than the observed on radar image. Even this way, cumulated rainfall values do not seem to differ significantly between them. Q-Q plot shows that both datasets have similar distributions (Fig. 7) with a scatter plot closer to a 1-1 line, except for high values which are less probable. Even though results will be improved with an analysis of the spatial distribution of rainfall over the ellipse, they are quite acceptable taking into account the simplicity of the assumption. This implies that simplifying convective structures by means of elliptical cells with constant mean precipitation value over them is a good approximation of reality.

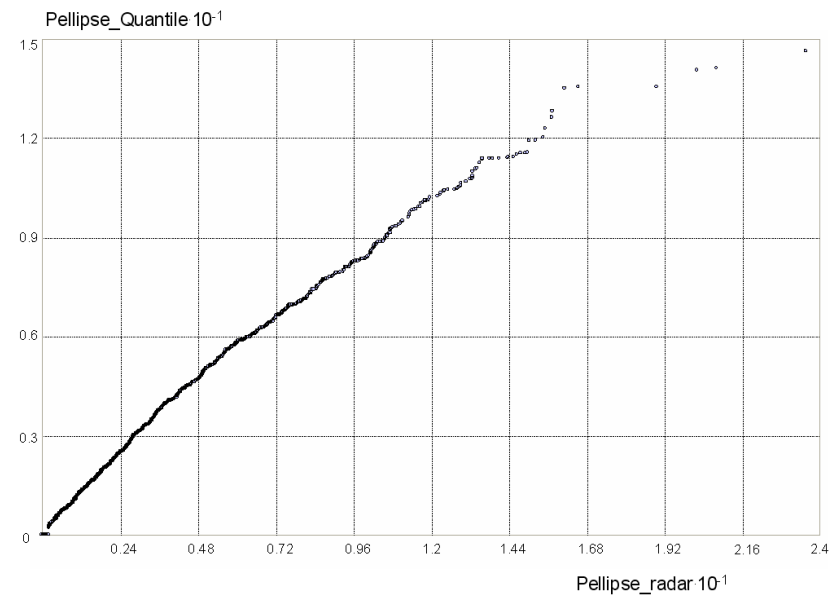

Fig. 7. Q-Q plot for the rainfall chart obtained from the elliptical cells considering mean precipitation constant over the cell, against the observed rainfall chart obtained form radar (considering only convective precipitation). Values are obtained by pixel for the $15 / 10 / 1996$ in $4 \mathrm{~h} 20 \mathrm{~min}$.

\section{Conclusions}

Convective structures associated to heavy rainfall events recorded in Catalonia between 1996 and 2000, have been analysed as a first step in the generation of a spatio-temporal rainfall model under a meteorological point of view. In this model, precipitation structures have been determined by means of 2-D radar algorithms through which a distinction between stratiform and convective precipitation is made.

Each convective cell has been described by its dimensions, orientation and precipitation over its area. For these parameters statistical distributions have been fitted to the observed 
ones. Several statistical distribution functions have been tested in order to find the best fit. Some of the functions tested are: Normal, Lognormal, Weibull, and Gamma distributions. Parameters of these functions have been obtained using the Maximum likelihood estimation (MLE) method. The distribution selected for each variable has been the distribution that best fitted each histogram. These distributions will be used to randomly generate simulated rainfall fields similar to the observed in the statistical sense.

The geometrical parameters of convective structures have been obtained by considering the elliptical cell assumption. Statistical analysis shows that most of the convective structures have small dimensions with major and minor axis mean values of $7.79 \mathrm{~km}$ and $3.66 \mathrm{~km}$ respectively. Frequency distributions of these parameters can be fitted by a GEV distribution of type II, also known as Fréchet distribution. The area of the convective structures lies between $32 \mathrm{~km}^{2}$ and $2380 \mathrm{~km}^{2}$, with a mean value of $107.19 \mathrm{~km}^{2}$. The major concentration of structures with small areas is related with the predominance of short life-cycles (less than $1 \mathrm{~h}$ ). A great part of the cases that have exceeded $1000 \mathrm{~km}^{2}$ produced floods, like the events of 14 September 1999, or 23 January 1996. The probability density function that best fits the distribution of frequencies observed for the area is the Generalized Pareto. This distribution is different from the one obtained by De Lannoy et al. (2005) (a normal distribution) as they have studied frontal rain systems in a small basin restricting their spatial extent to an area of $100 \mathrm{~km}^{2}$. Feral et al. (2000) who have studied some features of convective systems as well, also found extreme probability distribution functions as best fit for the dimensions of the rain cell.

The mean orientation of the cells is $80.92^{\circ}$ which means that most of them are facing North East. This parameter can be related to the mean winds at low and middle levels of the atmosphere. The result obtained agrees with the direction of the mean wind, responsible of the precipitation system movement in a great number of rainfall events in the region. Statistical analysis reveals that this parameter follows a GEV distribution of type III, also known as Weibull distribution. Mean areal precipitation over the cell has a mean value of $0.92 \mathrm{~mm}$ which corresponds to a mean areal intensity of $5.52 \mathrm{~mm} / \mathrm{h}$. The distribution of frequencies of this parameter is also represented by a GEV distribution of type II.

It is important to remark that all the parameters are statistically described by extreme value functions. It can be explained by the fact that some of the cases studied were extreme events with convective structures exceeding mean parameter values.

The fact of simplifying convective structures by means of elliptical structures with its mean precipitation constant over them has been tested by a Q-Q plot. This graphical technique has revealed that this assumption does not differ significantly from reality. Even so, the rainfall field obtained will represent more accurately the spatial variability observed in real cases with the inclusion of this variability in the model.
One of the considerations to take in a future work in order to improve rainfall modelling is the study of stratiform precipitation. In this case the rainstorm will be contemplated as a big elliptical stratiform structure enclosing convective structures. Spatial distribution of convective structures into the rainstorm will have to be evaluated. Cumulated rainfall charts obtained with this assumption will be improved, as stratiform precipitation (ignored in this work) is very important in some events with low intensities but long duration in time. The inclusion of different rainfall patterns assure a more realistic representation of reality needed to improve the results obtained by hydrological models.

Future research should also include the analysis of the movement of the cells described by their velocity and direction.

Results show a good modelling of convective precipitation, which is very important in flash-flood production (the most common in the region).

Acknowledgements. Authors thank the Agencia Catalana de l'Aigua and the Meteorological Regional Center of the INM in Catalonia for the rainfall and radar data provided, respectively. This study has been carried out in the framework of the agreement with the CEDEX "Obtención de un modelo de tormentas para su aplicación en el cálculo de caudales máximos en España. Desarrollo y aplicación del modelo para las cuencas de estudio", the European Project FLASH (FP6-2005-Global-4 (no. 036852)) and in the Spanish project SEVERUS (CGL2006-13372-C02-02). Finally, special thanks to Manel Ceperuelo and to Aitor Atencia for their help with radar and statistical analysis, respectively.

Edited by: C. de Michele

\section{References}

Barnolas, M. and Llasat, M. C.: A flood geodatabase and its climatological applications: the case of Catalonia for the last century, Nat. Hazards Earth Syst. Sci., 7, 271-281, 2007, http://www.nat-hazards-earth-syst-sci.net/7/271/2007/.

Biggerstaff, M. I. and Listemaa, S. A.: An Improved Scheme for Convective/Stratiform Echo Classification Using Radar Reflectivity, J. Appl. Meteorol., 39(12), 2129-2150, 2000.

Capsoni, C., Fedi, F., Magistroni, C., Paraboni, A., and Pawlina, A.: Data and theory for a new model of the horizontal structure of rain cells for propagation applications, Radio Sci., 22(3), 395404, 1987.

Capsoni, C., D'Amico, M., and Locatelli, P.: Statistical properties of rain cells in the Padana Valley, J. Atmos. Oceanic Tech., 25(12), 2230-2244, 2008.

Ceperuelo, M., Llasat, M. C., and Rigo, T.: Rainfall events and Hailstorms Analysis Program (RHAP), Adv. Geosci., 7, 205213, 2006, http://www.adv-geosci.net/7/205/2006/.

Chumchean, S., Seed, A., and Sharma, A.: Correcting of radar mean field bias using Kalman filtering approach, J. Hydrol., 317, 123-137, 2006. 
Cox, D. R. and Isham, V.: A simple spatial-temporal model of rainfall, Proc. Roy. Soc. Lond., A415, 317-328, 1988.

De Lannoy, G. J. M., Verhoest, N. E. C., and De Troch, F. P.: Characteristics of rainstorms over a temperate region derived from multiple time series of weather radar images, J. Hydrol., 307, 126-144, 2005.

García-Bartual R. and Marco, J.: A stochastic model of the internal structure of convective precipitation in time at a raingauge site, J. Hydrol., 118, 129-142, 1990.

García-Bartual, R. and Schneider, M.: Estimating maximum expected short-duration rainfall intensities from extreme convective storms, Phys. Chem. Earth Pt. B, 26(9), 675-681, 2001.

Krajeswki, W. F. and Smith, J. A.: Radar hydrology: rainfall estimation, Adv. Water Resour., 25, 1387-1394, 2002.

Feral, L., Mesnard, F., Sauvageot, H., Castanet, L., and Lemorton, J.: Rain cells shape and orientation distribution in South-West of France, Phys. Chem. Earth Pt. B, 25(10-12), 1073-1078, 2000.

Llasat, M. C.: An objective classification of rainfall events on the basis of their convective features: Application to rainfall intensity in the north-east of Spain, Int. J. Climatol., 21, 1385-1400, 2001.

Llasat, M. C., Ceperuelo, M., and Rigo, T.: Rainfall regionalization on the basis of the precipitation convective features using a raingauge network and weather radar observations, Atmos. Res., 83, 415-426, doi:10.1016/j.atmosres.2005.08.014, 2007.

Marshall, J. S. and Palmer, W. M. K.: The distribution of raindrops with size, J. Meteorol., 5, 156-166, 1948.

Morin, E. and Gabella, M.: Radar-based quantitative precipitation estimation over Mediterranean and dry climate regimes, J. Geophys. Res., 112, D20108, doi:10.1029/2006JD008206, 2007.

Morin, E., Goodrich, D. C., Maddox, R. A., Gao, X., Gupta, H. V., and Sorooshian, S.: Rainfall modelling for integrating radar information into hydrological model, Atmos. Sci. Lett., 6(1), 2330, 2005.

Morin, E., Goodrich, D. C., Maddox, R. A., Gao, X., Gupta, H. V., and Sorooshian, S.: Spatial patterns in thunderstorm rainfall events and their coupling with watershed hydrological response, Adv. Water Resour., 29, 843-860, 2006.

Northrop, P. J.: A clustered spatial-temporal model of rainfall, P. Roy. Soc. Lond., A454, 1875-1888, 1998.

Rebora, N. and Ferraris, L.: The structure of convective rain cells at mid-latitudes, Adv. Geosci., 7, 31-35, 2006, http://www.adv-geosci.net/7/31/2006/.
Rigo, T. and Llasat, M. C.: A methodology for the classification of convective structures using meteorological radar: Application to heavy rainfall events on the Mediterranean coast of the Iberian Peninsula, Nat. Hazards Earth Syst. Sci., 4, 59-68, 2004, http://www.nat-hazards-earth-syst-sci.net/4/59/2004/.

Rigo, T. and Llasat, M. C.: Analysis of mesoscale convective systems in Catalonia using meteorological radar for the period 1996-2000, Atmos. Res., 83, 458-472, 2007.

Rodriguez-Iturbe, I., Cox, D. R., and Isham, V.: Some models for rainfall based on stochastic point processes, Proc. Roy. Soc. Lond., A410, 269-88, 1987.

Rodriguez-Iturbe, I., Cox, D. R., and Isham, V.: A point process model for rainfall: further developments, Proc. Roy. Soc. Lond., A417, 283-98, 1988.

Salsón, S. and Garcia-Bartual, R.: A space-time rainfall generator for highly convective Mediterranean rainstorms, Nat. Hazards Earth Syst. Sci., 3, 103-114, 2003, http://www.nat-hazards-earth-syst-sci.net/3/103/2003/.

Sánchez-Diezma, R.: Optimización de la medida de lluvia por radar meteorológico para su aplicación hidrológica, Ph. D. Thesis, Universitat Politecnica de Catalunya, 313 pp., 2001.

Steiner, M., Houze Jr., R. A., and Yutter, S. E.: Climatological Characterization of Three-Dimensional Storm Structure from Operational Radar and Rain Gage Data, J. Appl. Meteor., 34(9), 19782007, 1995.

Syed, K. H., Goodrich, D. C., Myers, D. E., and Sorooshian, S.: Spatial characteristics of thunderstorm rainfall fields and their relation to runoff, J. Hydrol., 271, 1-21, 2003.

Trapero, L., Bech, J., Rigo, T., Pineda, N., and Forcadell, D.: Uncertainty of precipitation estimates in convective events by the Meteorological Service of Catalonia radar network, Atmos. Res., 93(1-3), 408-418, 4th European Conference on Severe Storms 4ECSS, 4th European Conference on Severe Storms, 2009

Von Hardenberg, J., Ferraris, L., and Provenzale, A.: The shape of convective rain cells, Geophys. Res. Lett., 30(24), 2280, doi:10.1029/2003GL018539, 2003.

Wheater, H. S., Isham, V. S., Cox, D. R., Chandler, R. E., Kakou, A., Northrop, P. J., Oh, L., Onof, C., and Rodriguez-Iturbe, I.: Spatial-temporal rainfall fields: modelling and statistical aspects, Hydrol. Earth Syst. Sci., 4, 581-601, 2000, http://www.hydrol-earth-syst-sci.net/4/581/2000/.

Willems, P.: A spatial rainfall generator for small spatial scales, J. Hydrol., 252, 126-144, 2001. 